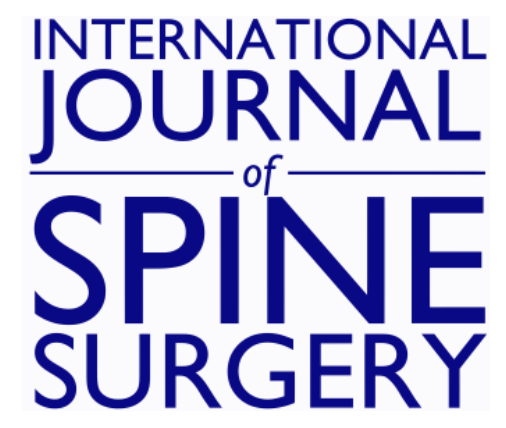

\title{
Percutaneous Transpedicular Lumbar Endoscopy: A Case Report
}

Priyank Uniyal, Gun Choi and Bhushan Khedkkar

Int J Spine Surg 2016, 10 ()

doi: https://doi.org/10.14444/3031

http://ijssurgery.com/content/10/31

This information is current as of April 26, 2023.

Email Alerts Receive free email-alerts when new articles cite this article. Sign up at:

http://ijssurgery.com/alerts

The International Journal of Sbine Surgerhy 2397 Waterbury Circle, Suite 1,

Aurora, IL 60504, Phone: +1-630-375-1432

(C) 2016 ISASS. All Rights Reserved. 


\section{Percutaneous Transpedicular Lumbar Endoscopy: A Case Report}

Priyank Uniyal, DNB ortho, Gun Choi, MD, PhD, Bhushan Khedkkar, DNB ortho

Pohang Wooridul Hospital, Pohang, Korea

\section{Abstract}

Introduction

Since Kambin introduced the concept of percutaneous transforaminal disc surgery in 1973, there has been numerous advances in the field of spine endoscopy and the concept of central debulking of the disc has changed to targeted fragmentectomy and disc preservation.

The lumbar disc fragments which are down migrated and to the medial aspect of the pedicle are extremely challenging to deal by transforaminal approach even after foraminoplasties and by various other approaches. Therefore most spine surgeons prefer open procedures which requires extensive removal of pars and facet leading to the risk of instability.

\section{Aims and objectives}

To describe a safe and effective technique for lumbar intra-canal high grade down migrated disc herniation, medial to the pedicle by transpedicular endoscopy.

\section{Methods and treatment}

Two patients underwent percutaneous transpedicular lumbar endoscopy under local anaesthesia for high grade down migrated disc herniation and for discal cyst at the medial aspect of pedicle respectively.

Results

We achieved the complete successful decompression by percutaneous transpedicular lumbar endoscopy.

\section{Conclusion}

Authors found this technique very promising in complete removal of disc material under direct visualisation for high grade down disc herniations.

KEYWORDS: SPINE ENDOSCOPY, HIGH GRADE DOWN MIGRATED DISC HERNIATION, PERCUTANEOUS TRANSPEDICULAR LUMBAR ENDOSCOPY VOLUME 10 ARTICLE 31 DOI: 10.14444/3031

\section{Introduction}

Kambin and Zhou in 1997 published their first successful outcomes of arthroscopic microdiscectomy for contained and non migrated sequestered disc herniation. Earlier in 1983 Kambin and Gellman reported their first experience of percutaneous lumbar discectomy (PELD). ${ }^{2}$ Since last three decades the indications of PELD are continuously expanding with inclusions such as non contained sequestrated or migrated disc herniations..$^{3-5}$ Earlier Choi Gun et a $\mathrm{a}^{6-8}$ had described various endoscopic techniques for the removal of high grade down migrated lumbar disc fragments. With the introduction of new fine endoscopic drills, the bone resection is meticulous under direct vision which facilitates the grabbing and easy removal of the migrated disc. In this Case report, we introduce and describe our new surgical technique of Percutaneous transpedicular lumbar endoscopy. To authors knowledge, previously described transpedicular approaches were for the thoracic spine $e^{9-10}$ only but none of them has mentioned this technique for lumbar spine.

\section{Case illustrations}

\section{Case 1}

A 59 year old man presented with low back pain with radiation to posterior aspect of right thigh and calf (VAS 7). Physical examination revealed a positive 
SLR test on right side. MRI lumbar spine showed L3-4 right paracentral disc herniation with down migration upto the inferior border of right L4 pedicle, compressing L4 root (Figure 1). On CT scan it was a soft disc without calcification. We performed a transpedicular PELD through right side of L4 pedicle. Postoperatively, the patient's symptoms improved (VAS 2); MRI and CT demonstrated complete removal of disc herniation and L4 nerve root decompression (Figure 2). Intraoperative findings can be seen in Figure 3.

Case 2

A 36 year old man presented with complains of low back ache with left leg radiculopathy and VAS score of 9 for leg pain. Physical examination demonstrated

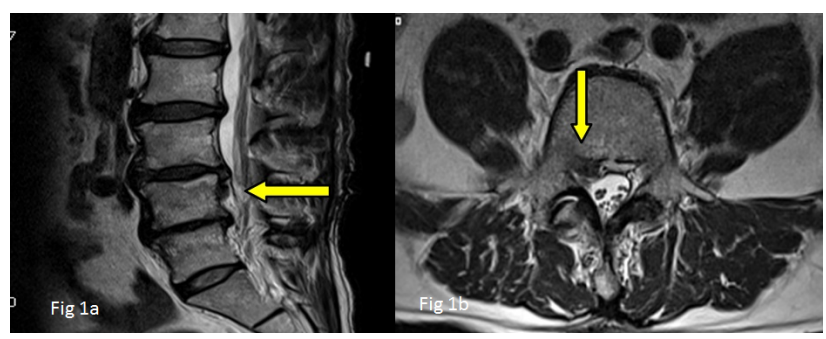

Fig. 1. Preoperative MRI. 1a: saggital T2W down migrated disc, 1b: axial $\mathrm{T} 2 \mathrm{~W}$ with down migrated disc herniation upto the inferior pedicle level.

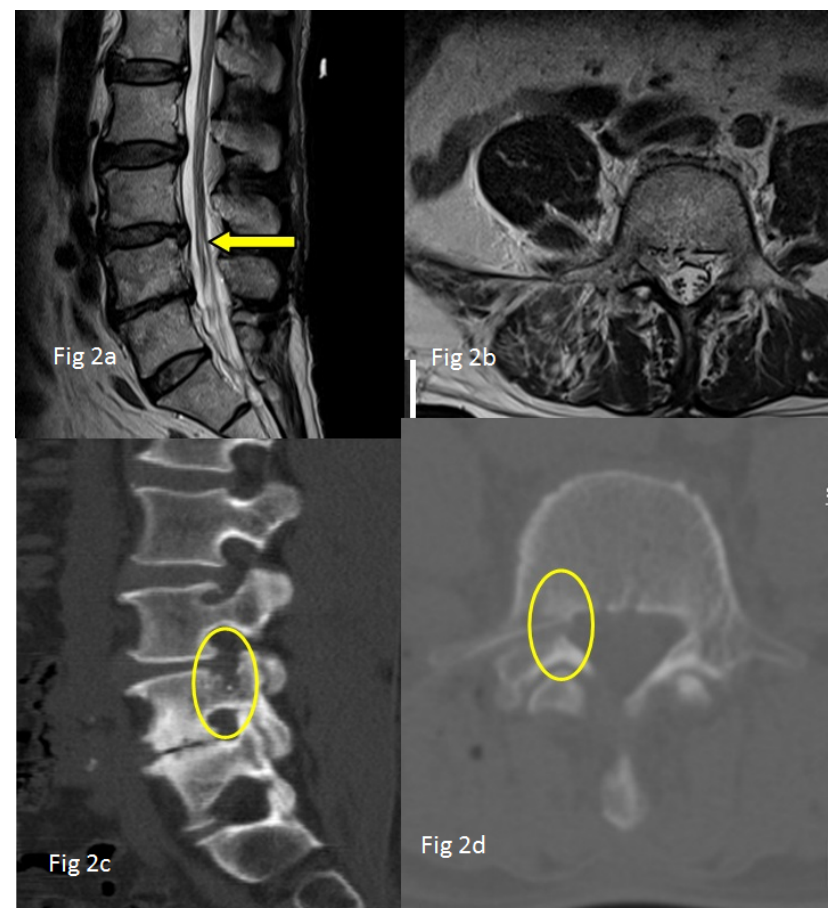

Fig. 2. Postoperative MRI and CT. 2a: saggital T2W removal of herniated disc. 2b: axial T2W showing complete decompression upto the inferior level of the pedicle. $2 c \mathcal{E} 2 \mathrm{~d}$ : saggital and axial CT shows the entry of transpedicular approach through the pedicle (yellow circle). a positive straight leg raising (SLR) sign on the left side. There was objective weakness of tibialis anterior graded as $4 / 5$ on MRC scale. Magnetic resonance
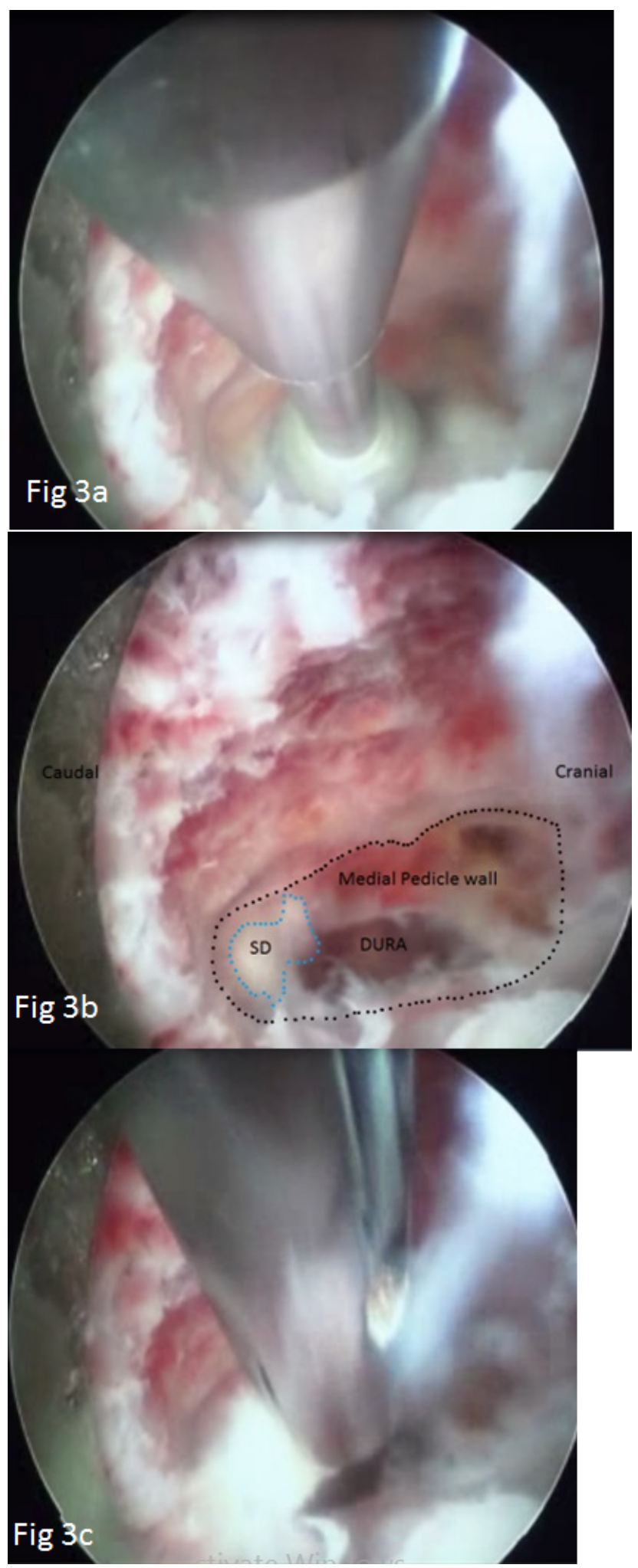

Fig. 3. Endoscopic view. 3a: drilling of medial pedicular wall 3b: tail of sequestered disc (SD); dotted line demarcates the medial pedicle wall. $3 c$ : removal of herniated fragment with an endoscopic forceps. 
imaging (MRI) of lumbar spine revealed left discal cyst L3-4 level extending upto lower border of L4 pedicle compressing left L4 root (Figure 4). A computed tomography (CT) scan showed non calcified lesion without bony erosion. We performed a transpedicular percutaneous endoscopic lumbar removal discal cyst through left L4 pedicle. The L4 nerve root was compeletely decompressed and patient's symptoms relieved immediately after the surgery (VAS score 2). Post operatively MR images (Figure 5) showed complete removal of discal cyst and decompression achieved. Endoscopic findings is shown in Figure 6.

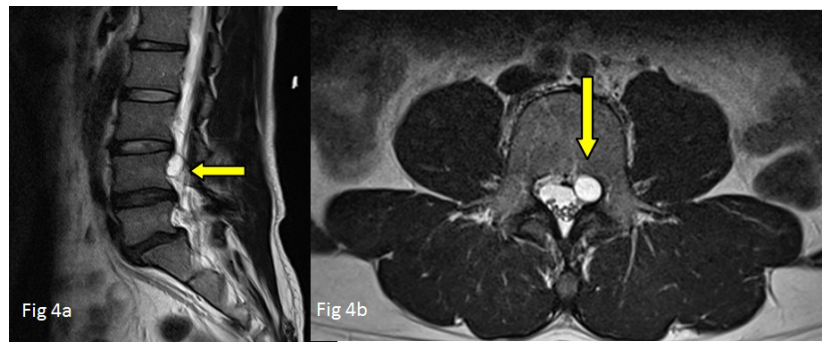

Fig. 4. Preoperative MRI. 4a: saggital T2W discal cyst, 4b: T2W axial showing discal cyst at the medial aspect of L4 left pedicle.

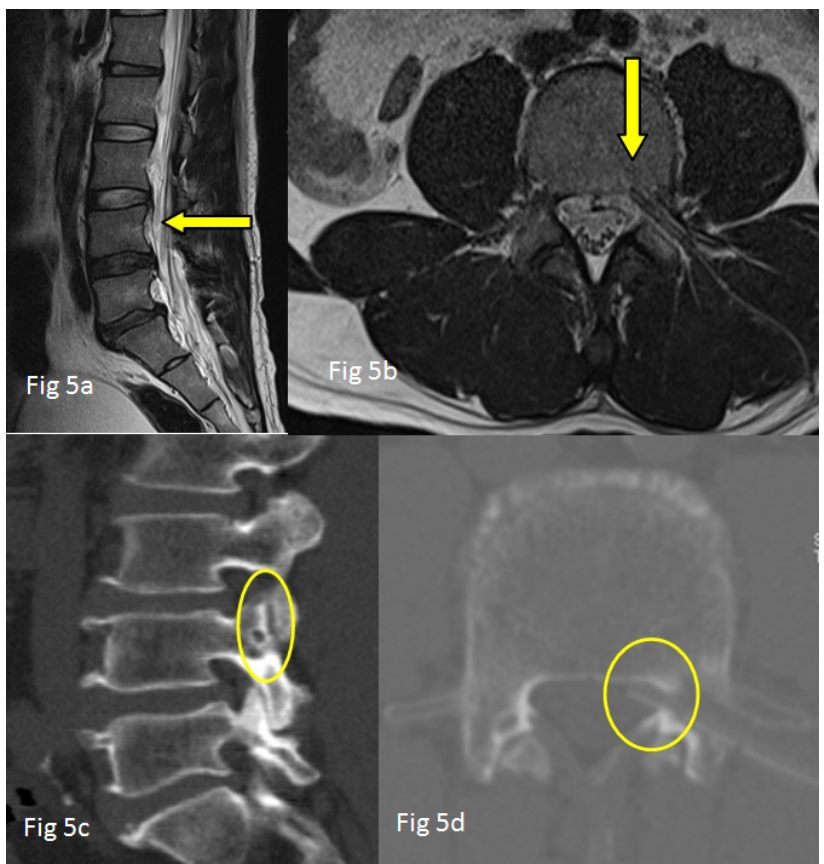

Fig. 5. Postoperative MRI \& CT. 5a: Complete removal of discal cyst on sagg T2W; 5 b: T2W axial complete decompression and drain placed in situ; $5 c \& 5 \mathrm{~d}$ : saggital and axial CT shows the transpedicular entry point and trajectory through the pedicle (yellow circle).
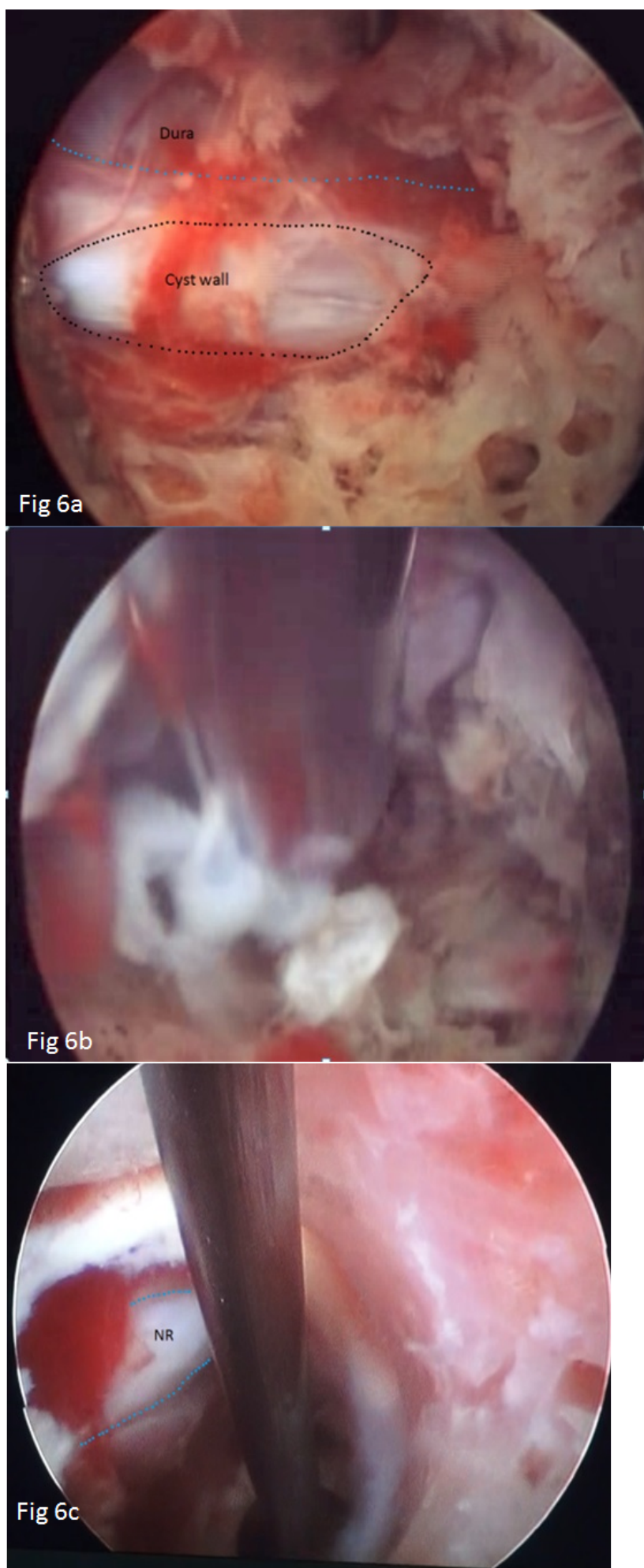

Fig. 6. Endoscopic view. 6a: the black dotted line shows the ruptured and collapsed discal cyst wall, the blue dotted line demarcates dura. $6 \mathrm{~b}$ : tail of herniated disc fragment being grabbed by an endoscopic forceps. 6c: canal space after removal of discal cyst (NR - nerve root) 


\section{Technical aspects}

Approach-Transpedicular (lumbar)

Armamentarium (Figure 7)

- Endoscope - New lumbar endoscopic spine system(Spine doctors, South Korea). Relevant measurements: $30^{\circ}$; length $208 \mathrm{~mm}$; working channel 4.2 $\mathrm{mm}$; outer diameter $6.5 \mathrm{~mm}$.

- Spinal Needle 18 Gauge 7.5 inch

- Guide wire $0.8 \mathrm{~mm}$

- Triphines $3 \mathrm{~mm}, 5 \mathrm{~mm}$

- Obturator $6.5 \mathrm{~mm}$

- Cannula $7.5 \mathrm{~mm}$

- Endoscopic drill- diamond tip $3 \mathrm{~mm}$

- Endoscopic forceps- working length $320 \mathrm{~mm}$ and diameter $3.5 \mathrm{~mm}$

- Radiofrequecy cautery (trigger flex elliquence,USA)

- Ho-YAG laser with side firing probe (lumenis 100W)

- A blunt tip probe

\section{Technique}

Anesthesia. Local anaesthesia with conscious sedation (initially intravenous Midazolam $0.05 \mathrm{mg} / \mathrm{kg}$ and $0.8 \mathrm{mg} / \mathrm{kg}$ Fentanyl and repeated if required) was used.

Position. Patient was placed in prone position with hips and knees in flexion on radiolucent Jackson table.

Level marking. The target level is marked under fluo-

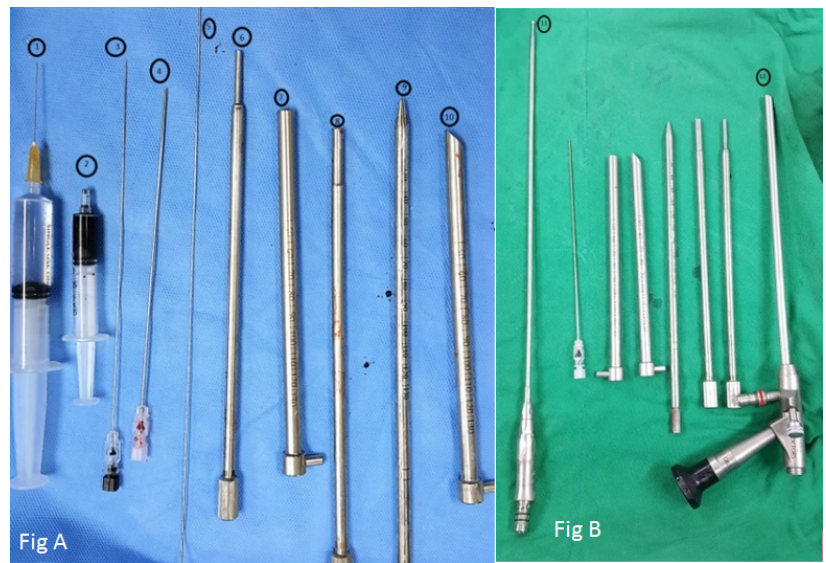

Fig. 7. 1) Local anesthetic 2) Dye for discography 3) $23 \mathrm{G}$ discography needle 4) $18 \mathrm{G}$ endoscopy needle 5) guide wire, 6) \& 8) Triphines, 7) \& 10) cannula 9) obturator 11) Endoscopic Drill 12) Endoscope. roscopic guidance.

Discography. Discography is performed by posterolateral approach with a mixture of contrast and dye (Ratio omnipaque:indigocarmine:normal saline of 2:1:2 respectively) and extravastion of contrast-dye is noted (Figure 5a).

Entry point. Pedicle 2'o clock to 3'o clock for right side and 9'o clock to 10 'o clock for left side on antero-posterior (AP) view depending on the extent of down migration.

Skin infiltration. With $8 \mathrm{ml}$ to $10 \mathrm{ml} 1 \%$ lidocaine, skin, deep tissue and periosteum of pedicle is infiltrated (1-2 $\mathrm{ml}$ for skin and subcutaneous tissue, 7-9 $\mathrm{ml}$ for deep infiltration).

Needle insertion. An 18G 7.5 inch spinal needle is inserted from the posterolateral approach transpedicularly and advanced upto the posterior vertebral body wall on lateral view and medial pedicle wall in AP view fluoroscopy (Figure 8a \& Figure 8b). The starting point of needle insertion from skin is decided from preoperative MRI and CT scans. The trajectory of transpedicular endoscopy is shown in Figure 9.

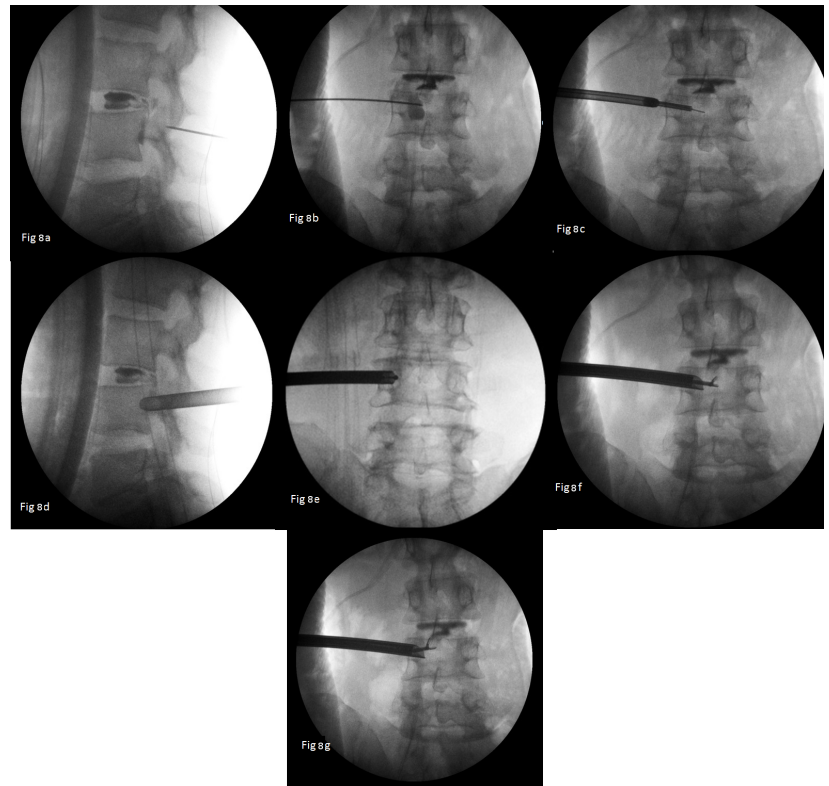

Fig. 8. Intraoperative fluoroscopy. 8a: discography with extravasation of the dye; $8 \mathrm{~b}$ : needle placement transpedicularly; $8 \mathrm{c}$ : reaming by triphine; $8 \mathrm{~d}$ : final cannula placement; 8e: endoscopic drilling of medial pedicle wall, $8 \mathrm{f} \varepsilon$ $8 \mathrm{~g}$ : endoscopic forceps placement during removal of herniated disc fragment. 
Serial dilation and triphines. A blunt tip guide wire of $0.8 \mathrm{~mm}$ is exchanged with the spinal needle. A stab incision is made over the guide wire and triphine of size $3 \mathrm{~mm}$ is docked at the starting bony point and is advanced further in, while rotating it in a clockwise manner. Once hole is drilled transpedicularly, its trajectory is confirmed in AP and lateral view of fluoroscopy and trajectory is widened with a larger trephine of size $5 \mathrm{~mm}$ (Figure 8c).

Obturator and Cannula placement. A $6.5 \mathrm{~mm}$ obturator with a tapered end is passed over the guide wire. Tapered end of the obturator facilitates the easy insertion, now guide wire is removed and a $7.5 \mathrm{~mm}$ bevelled cannula is passed over the obturator. The obturator is removed and the bevel of the cannula is kept facing medially as shown in (Figure 8d).

Endoscopy. A $6.5 \mathrm{~mm}, 30^{\circ}$ rigid working chanel endoscope (Spine Doctors, South Korea) is introduced into the cannula. Medial pedicle wall is identified (12'o clock) and confirmed on fluoroscopy and drilling is started with a $3 \mathrm{~mm}$ endoscopic drill (diamond burr) (Figure 8e). Now the intra-canal space is entered from the medial wall of pedicle. Epidural vessels are coagulated with $R F$ and hemostasis is achieved. A blunt probe or a hook is inserted and the sequestered disc fragments are identified and removed. Disc fragments are removed with an endoscopic forceps (Figure of \& Figure 8g). Final hemostasis is achieved and a drain is placed in situ. Wound is closed with ethilon 3-0.

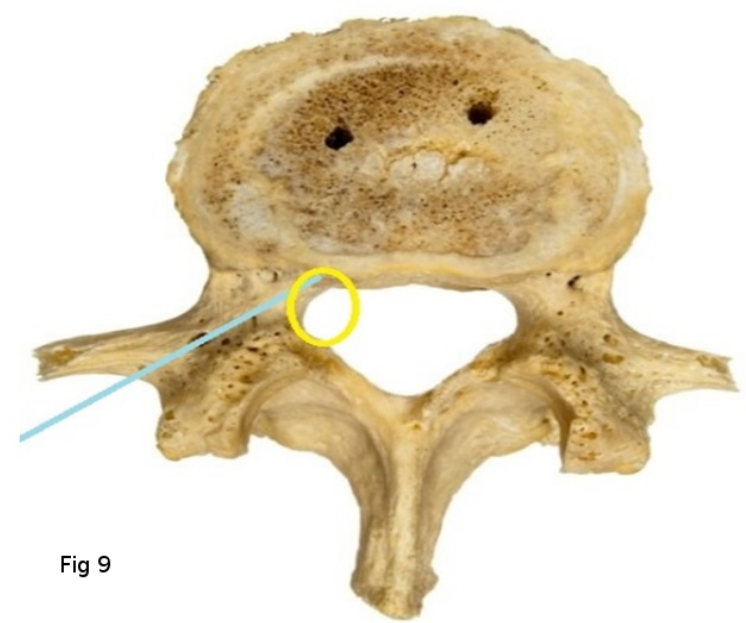

Fig. 9. The blue line indicates the trajectory of transpedicular endoscopy and yellow circle denotes the target point which has to be drilled endoscopically.

\section{Discussion}

Our technique is very promising as we can reach the intra-canal space transpedicularly and can remove the pathology under direct vision. Only the medial wall of the pedicle is drilled for the access to the herniated site and the defect will fill over period of time as bone formation occurs. The disc ruptures through posterior longitudinal ligament and enters the anterior epidural space and can migrate cranially or caudally. ${ }^{6,11,12}$ These migrated disks are commonly sequestrated ones and are medial to the pedicle, so the chances of missing of the fragments are high with transforminal PLED procedures. With the introduction of new flexible endoscopic forceps we have increased the span of our technique (Figure 8g). The concept of the central debulking of the disc has now changed to targeted fragmentectomy and disc preservation. ${ }^{13}$ As we have shown removal of down migrated disc herniation and discal cyst by our technique, an appropriate indication of this technique is an acute soft disc herniation with high grade down migration disc medial to the pedicle. Results are better with the disc fragments on the shoulder aspect of traversing root. The herniations are easy to remove when it is in single fragment and in close proximity to the medial wall of pedicle. Difficulties could be found when the disc fragment axillary in location to the traversing nerve root and is the absolute contraindication of this technique. Other relative contraindications or we can say difficult ones include hypoplastic pedicle, severe canal compromise with high grade migration with neuro deficits, calcified disc fragments, high iliac crest, severe osteoporosis and centrally down migrated intra-canal herniation. Other pathologies which can be dealt with this technique are drainage of epidural abscess, hematoma, and taking intra-canal biopsies. For both of the cases, our operating time was average 35 minutes.

Critical analysis of radiology is very essential for the planning of transpedicular trajectory to the medial wall of the pedicle. Perfect needle placement is the only key for the success in this surgery. The trajectory is just tangential to the medial wall of the pedicle (Fig 8) and the opening to the intra-canal surface is made through an endoscopic drill rather than triphines under direct vision and in a precise manner. 
For the fragment lying on the inferior aspect of the pedicle, cranio-caudal direction of needle has to be selected and vice versa. Evaluation of the pedicle dimensions are measured to confirm the size of endoscope to be used. Anatomical characteristics of lumbar pedicle varies according to the different levels (Table 1). ${ }^{14}$

As this is an outpatient procedure under local anaesthesia, the patient can be mobilized on the same post operative day and can be discharged.

Authors recommend this technique as an alternative to the transforaminal PELD in the patients with aberrant location of the exiting nerve root or blood vessel in the neural foramen, compromised dimensions of the foramen and in the patients with high iliac crest.

\section{Conclusion}

The transpedicular endoscopy is a new and highly efficient technique to remove the high grade down migrated disc herniations and which are medial and extending to the inferior margin of the pedicle.

\section{References}

1. Kambin P, Zhou L: Arthroscopic discectomy of the lumbar spine Clin Orthop Relat Res. 1997

Apr;(337):49-57

2. Kambin P, Gellman H: Percutaneous lateral discectomy of lumbar spine: a preliminary report. Clin Orthop 1983, 174:127-132.

3. Yeung A, Yeung C: Advances in endoscopic disc and spine surgery: foraminal approach. Surg Technol Int 2003, 11:255-263.

4. Yeung A, Tsou P: Posterolateral endoscopic exci-

Table 1. Anatomic characteristics of lumbar pedicle.
\begin{tabular}{|l|r|r|r|}
\hline Level & $\begin{array}{r}\text { Mean transverse di- } \\
\text { ameter (millimetres) }\end{array}$ & $\begin{array}{r}\text { Mean medial an- } \\
\text { gulation (degrees) }\end{array}$ & $\begin{array}{r}\text { Mean sagittal (caudal) } \\
\text { angulation (degrees) }\end{array}$ \\
\hline L1 & 8 & 14.5 & 2.6 \\
\hline L2 & 7.8 & 14.2 & 2.7 \\
\hline L3 & 10.2 & 18.5 & 2.7 \\
\hline L4 & 13.4 & 16.6 & 3.9 \\
\hline L5 & 18.0 & 24.6 & 5.5 \\
\hline
\end{tabular}

sion for lumbar disc herniation: Surgical technique, outcome, and complication in 307 consecutive cases. Spine (Phila Pa 1976) 2002;27(7):722-31

5. Ahn Y, Lee SH, Park WM, Lee HY (2003) Posterolateral percutaneous endoscopic lumbar foraminotomy for L5-S1 foraminal or lateral exit zone stenosis. Technical note. J Neurosurg 99: 320-323. 6. Choi G, Lee SH, Lokhande P, Kong BJ, Shim CS, Jung B, Kim JS Percutaneous endoscopic approach for highly migrated intracanal disc herniations by foraminoplastic technique using rigid working channel endoscope Spine (Phila Pa 1976). 2008 Jul 1;33(15):E508-15. doi: 10.1097/ BRS.0b013e31817bfa1a

7. Choi G, Prada N, Modi HN, Vasavada NB, Kim JS, Lee SH Percutaneous endoscopic lumbar herniectomy for high-grade down-migrated L4-L5 disc through an L5-S1 interlaminar approach: a technical note Minim Invasive Neurosurg. 2010 Jun;53(3):147-52. doi: 10.1055/s-0030-1254145. Epub 2010 Aug 31.

8. Kim JS, Choi G, Lee SH Percutaneous endoscopic lumbar discectomy via contralateral approach: a technical case report Spine (Phila Pa 1976). 2011 Aug 1;36(17):E1173-8. doi: 10.1097/ BRS.0b013e3182264458.

9. Jho HD Endoscopic transpedicular thoracic discectomy Neurosurg Focus. 2000 Oct 15;9(4):e4. 10. Bilsky MH Transpedicular approach for thoracic disc herniations Neurosurg Focus. 2000 Oct 15;9(4):e3.

11. Kuzeyli K, Cakir E, Usul H, et al. Posterior epidural migration of lumbar disc fragments: report of three cases. Spine 2003;28:E64-E67.

12. Schellinger D, Manz HJ, Vidic B, et al. Disk fragment migration. Radiology 1990;175:831-6.

13. Faulhauer K, Manicke C. Fragment excision versus conventional disc removal in the microsurgical treatment of herniated lumbar disc. Acta Neurochir (Wien) 1995;133:107-11.

14. Panjabi MM, Goel V, Oxland T, et al. Human lumbar vertebrae. Quantitative three- dimensional anatomy Spine 1992; 17(3):299-306.

\section{Disclosures \& COI}

The authors report no relevant disclosures or conflicts of interest. 


\section{Corresponding Author}

Priyank Uniyal, Pohang Wooridul Hospital, Pohang, Republic of Korea. priyank_uniyal@yahoo.com.

Published 7 September 2016.
This manuscript is generously published free of charge by ISASS, the International Society for the Advancement of Spine Surgery. Copyright $\odot 2016$ ISASS. To see more or order reprints or permissions, see http://ijssurgery.com. 